\title{
THE STUDY ON EFFECT OF TORQUE ON PISTON LATERAL MOTION
}

\author{
Vinay V. Kuppast ${ }^{1}$, S. N. Kurbet ${ }^{2}$, A. M. Yadawad ${ }^{3}$, G. K. Patil ${ }^{4}$ \\ ${ }^{1}$ Associate Professor, ${ }^{2}$ Professor \& Head, ${ }^{4}$ Associate Professor, Department of Mechanical Engineering, Basaveshwar \\ Engineering College, Bagalkot, Karnataka State, India, \\ nim.vinay@gmail.com, snkurbet@gmail.com,patilgk.krisna@gmail.com \\ ${ }^{3}$ Associate Professor, Department of Mechanical Engineering, National Institute of Engineering, Mysore, Karnataka \\ State,India, aravind_lata@gmail.com
}

\begin{abstract}
The studies of engine components reveal the cause for the engine vibration and noise. The piston slap due to the impact of the piston in the walls of the cylinder is considered as one of the predominant source of engine noise. In the present work engine performance characteristics are considered. The variation of the torque from minimum to maximum and the corresponding values of the engine performance parameters are logged. The effect of torque on engine speed and on piston movement is studied. The duration of the piston in cylinder for these input values ore also logged. The piston lateral movement is recorded by measuring the gap between cylinder inner wall and the piston skirt for the piston primary motion from TDC to BDC and vice versa. Finite element analysis is carried for von-Mises stress and x-directional displacement for the lateral displacement. The high stress region in the piston is emphasized for the study. It is found that near TDC region the engine is experiencing the maximum impact due to high torque which is the result of combustion pressure and also corresponds to the cause for piston lateral motion in this region.
\end{abstract}

Index Terms: engine torque, finite element analysis, lateral motion, and stress

\section{INTRODUCTION}

The automotive industries emphasis on the development of quieter engines to minimize noise and vibration, hence by improving performance contributions can be done to minimize the pollution. The present work is study the engine parts viz., piston considered as the main source or vibration and noise. Primary motion of engine part is due to combustion pressure in the combustion chamber which makes piston to move from TDC to BDC but this motion is linear in nature, this motion is desired in IC engine for transfer of motion from one part to another but this is not producing much vibration in engine as compare to secondary motion. Secondary motion of engine part is due to impact load of the combustion, and it is lateral motion of engine part while piston moving from TDC to BDC vice-versa. Lateral motion produced is not desired in IC engines because it produces piston slap and twisting movement in the engine.

The objectives of the present work is, to develop 3dimentional Finite Element (FE) model of piston for the piston motion considering regions; piston, piston before TDC, at TDC and after TDC, and to study stress distribution and deformation of piston in different regions. The multi-body dynamic analysis of the engine considering all the components is studied. The Torque data is obtained from the experiments conducted for the maximum pressure of 54.7 Bars. Then to find out the effect of pressure and torque on the strength of the piston and other engine components (MBD analysis) in terms of the stress induced, to predict the maximum displacement of piston for slap, which induces engine vibration and hence noise.

The engine performance characteristics will be considered for this analysis. The Kirloskar 4- stroke diesel engine is test run for different input parameters. The variation of the torque from minimum to maximum is tested. The corresponding values of the engine performance parameters are logged.

\subsection{Engine Specifications}

The I.C. engine specifications which are considered for the study are given in the Table-1. The engine is tested for a given operating conditions as $25 \%$ loading, $50 \%$ loading and $75 \%$ loading are most generally considered for engine design. In present study the readings for $75 \%$ loading is considered for MBD analysis. The corresponding stress values have been considered for the study of the lateral motion.

Table -1: Engine Specifications

\begin{tabular}{|l|l|}
\hline Description & Specification \\
\hline Engine & Kirloskar engine \\
\hline Bore & $80 \mathrm{~mm}$ \\
\hline Stroke & $110 \mathrm{~mm}$ \\
\hline Engine Speed & $1500 \mathrm{rpm}$ \\
\hline
\end{tabular}




\begin{tabular}{|l|l|}
\hline Compression ratio & $16.5: 1$ \\
\hline Test condition/Type & $\begin{array}{l}\text { Water cooled direct injection } \\
\text { diesel single cylinder engine }\end{array}$ \\
\hline
\end{tabular}

\section{MODELLING AND ANALYSIS}

Solid modeling is important because it is the key to obtaining productivity promises that computers offer designers.many tools are also used to create solid model in part design work bench in CATIA modeling software.

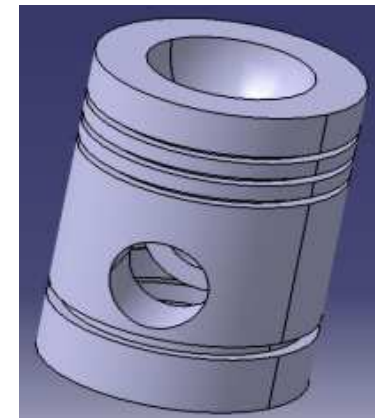

Fig -1: Solid model of piston

\subsection{Assembly Modelling}

In most engineering design the product of interest is a composition of parts formed into an assembly. Modeling and representing assemblies as well as analyzing assemblies are all relevant issues to geometric modeling and the CAD/CAM technology.

\subsection{Finite Element Modelling and Analysis}

The Steps in Finite Element (FE) modeling include; specify material properties, apply loads, identify boundary conditions, discretize the geometry to produce a finite element mesh, solve the system of linear equations, post processing and verifying results. The accuracy of the model and explains the simplifications that were made to obtain an efficient FE model. Using proper boundary conditions and type of loading are important since they strongly affect the results of the FE analysis. FE models are used for dynamic analysis considering the boundary conditions according to the specifications of the engine. The required geometric information for the mesh generation is collected by importing the IGES file of the model in Hypermesh-9. All the meshed components are tested for the quality of the mesh. After proving the quality of the mesh, the components are assembled to represent the IC engine system. Each component is meshed independently as shown in subsequent Fig-2 through Fig-6. The type and number of elements are shown in Table-2.

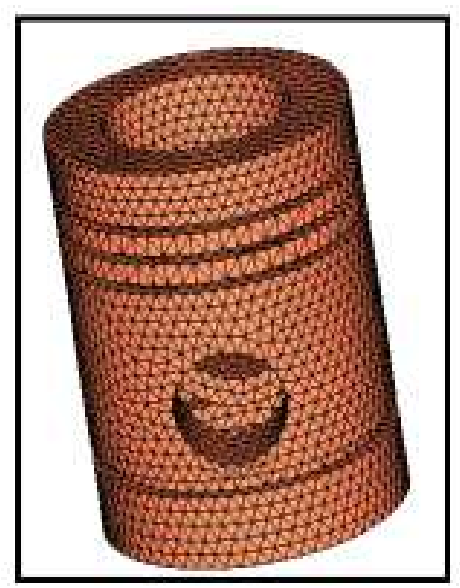

Fig -2: FE model of piston

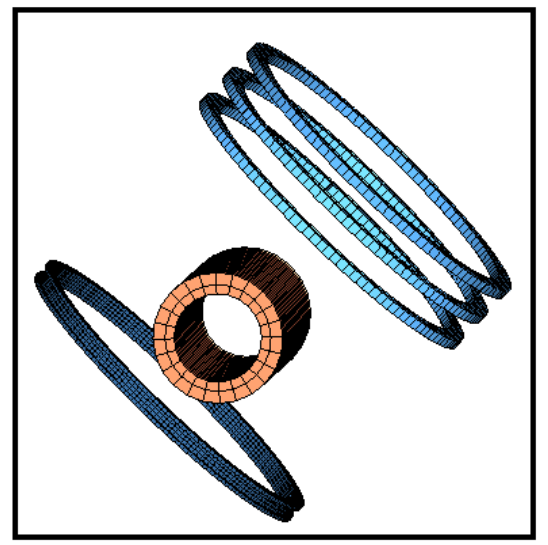

Fig -3: FE model of pin, compression and oil rings

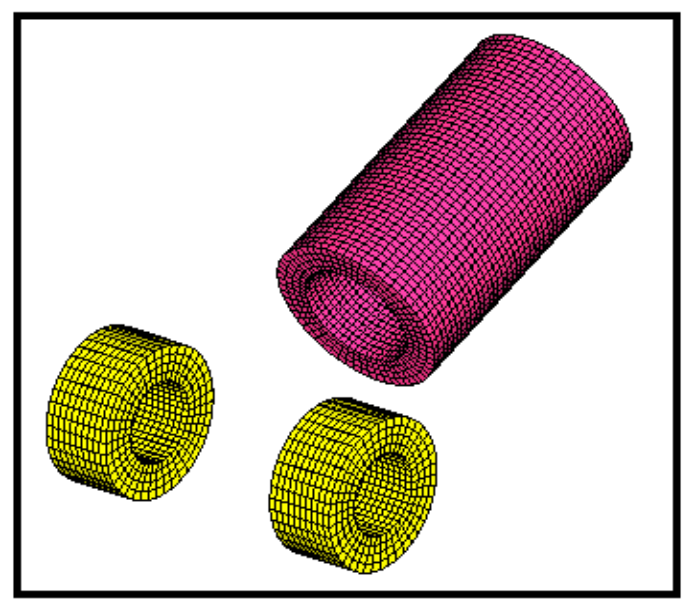

Fig -4: FE model of cylinder and bearing 


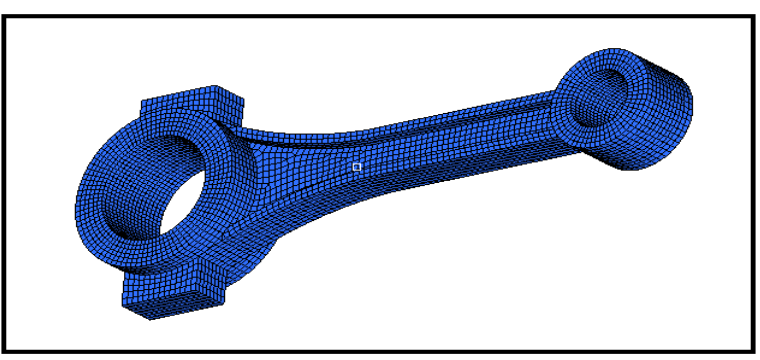

Fig -5: FE model of connecting rod

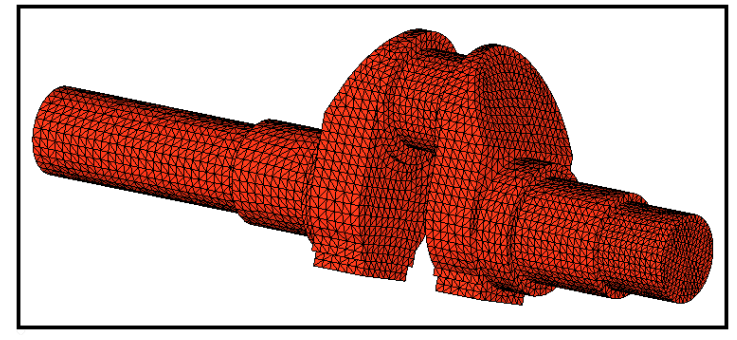

Fig -6: FE model of Crank Shaft

Table -2: Type and number of elements

\begin{tabular}{|l|l|l|}
\hline Component & Element type & $\begin{array}{l}\text { Number of } \\
\text { element }\end{array}$ \\
\hline $\begin{array}{l}\text { Connecting } \\
\text { rod }\end{array}$ & $\begin{array}{l}\text { Hexahedral, } \\
\text { Penta-element }\end{array}$ & 19951 \\
\hline Crank Shaft & Tetrahedral & 32334 \\
\hline Piston & Tetrahedral & 10320 \\
\hline Piston rings & Hexahedral & 960 \\
\hline Oil Rings & Hexahedral & 2412 \\
\hline Gudgeon pin & Hexahedral & 960 \\
\hline Cylinder & Hexahedral & 3200 \\
\hline Bearing & Hexahedral & 3200 \\
\hline \multicolumn{2}{|l|}{ Total Elements } & 73337 \\
\hline
\end{tabular}

The Multi Body Dynamic (MBD) analysis is carried out to understand the dynamic behaviour of the machine parts in an assembly in its running condition. The pressure on the piston varies with the crank angles when moving from TDC to BDC and the cycle repeats. This pressure data is considered for the force on the piston in the analysis. This in turn carried to the connecting rod and then to the crankshaft. Hence the engine components experience the gas force exerted on the piston. Here it is obvious to study the stress regions and displacements in different engine parts to predict the behaviour of the parts. This will reveal the lateral motion of the piston for different crank angle positions and is used to predict the piston slap. The different joints have to be defined between moving components of the engine. The details of the different joints defined are given in the Table- 3 .

Table -3: Types of Joint

\begin{tabular}{|l|l|}
\hline Type of Pair & Type of joint \\
\hline Piston - Cylinder & Translational \\
\hline Piston - Piston rings & Translational/cylindrical \\
\hline Piston - Gudgeon pin & Revolute \\
\hline $\begin{array}{l}\text { Connecting rod- } \\
\text { Gudgeon pin }\end{array}$ & Revolute \\
\hline $\begin{array}{l}\text { Connecting rod - Crank } \\
\text { shaft }\end{array}$ & Revolute \\
\hline Crank shaft - Bearing & Revolute \\
\hline Bearing - Ground & Fixed \\
\hline
\end{tabular}

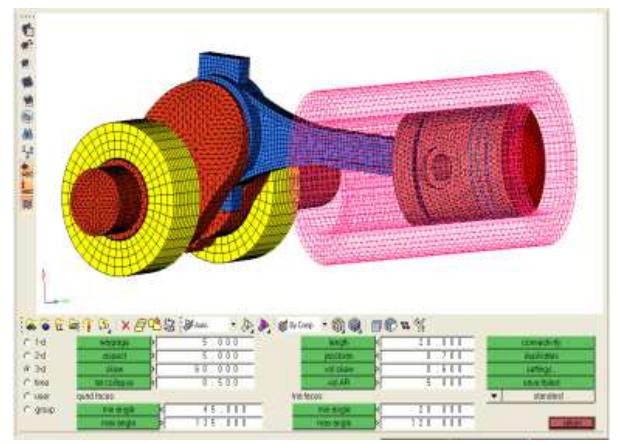

Fig -7: Assembled meshed model in Hypermesh with quality check

\section{RESULTS AND DISCUSSIONS}

The analysis is carried out for stress induced in the engine components and MBD analysis is carried out to understand the motions of the engine components relative to each other. The stress and displacement graphs have been considered to study the effect of gas pressure on the piston deformation at different crank angle position. The experiments are conducted for the given pressure of the engine. The variations of the pressure for different crank angles are noted.

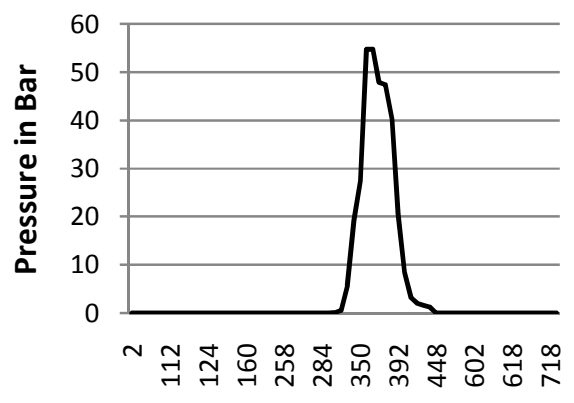

Crank Angle in degrees

Chart -1: Pressure v/s Crank Angle 
The Chart-1 shows the variation of the pressure for different crank angle rotation. The data is taken for the torque reading of $19.44 \mathrm{~N}-\mathrm{m}$ ( $75 \%$ loading). The engine speed is noted for the different values of the torque and is shown in the Table 4. These parameters are use to draw to understand the effect of pressure on the engine components for different crank rotation.

Table -4: Speed of engine for different torque

\begin{tabular}{|l|l|}
\hline Torque N-m & Speed rpm \\
\hline 4.86 & 1558 \\
\hline 8.56 & 1535 \\
\hline 11.32 & 1487 \\
\hline 19.12 & 1473 \\
\hline 19.48 & 1463 \\
\hline 19.87 & 1455 \\
\hline 19.44 & 1464 \\
\hline
\end{tabular}

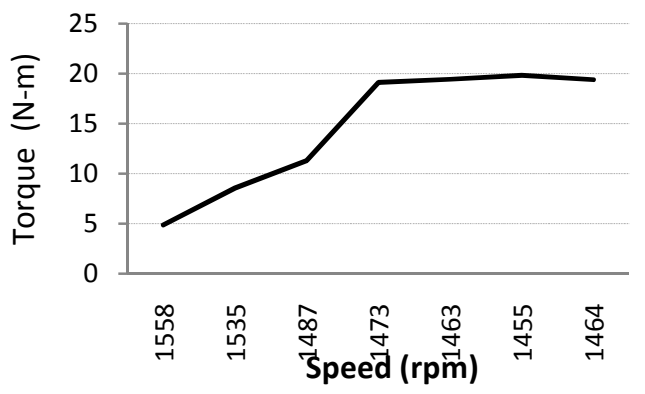

Chart -2: Torque V/S Speed

The torque of the engine gradually increases corresponding to the engine speed and then the speed becomes stable for higher torques (Chart-3). At this point the torque also becomes constant for constant value of the engine speed. It is observed from the engine data that the pressure increases at the TDC region and this trend of the pressure rise continues for the remaining values of the torque of the engine. After attaining constant speed ( $1487 \mathrm{rpm}$ to $1464 \mathrm{rpm}$ ) the torque also almost becomes constant. Hence for high engine speed torque is low and the torque becomes constant (around $19 \mathrm{~N}-\mathrm{m}$ ) for remaining period of the experiment with almost constant velocity. The peak combustion pressure region neat TDC witnessed the higher torque value also. Now it is desired to find out the piston $\mathrm{x}$-displacement and the piston high stress regions for lateral motion which induces lateral forces on the side walls of the cylinder (piston slap). For this study the indicated horse power (IP) and break horse power (BP) are noted to understand the variation of the IP and $\mathrm{BP}$ with engine torque. From the Chart-4 it is observed that as the brake horse power increase as the torque increases and it becomes constant for the remaining period. This indicates that the brake horse power is proportional to the engine speed. The gas pressure in this region has a maximum value and also the power of the engine is has the maximum corresponding to the higher value of torque.

Table -1: Engine test data

\begin{tabular}{|l|l|l|}
\hline Torque & BP kW & IP kW \\
\hline 4.86 & 0.79 & 2.18 \\
\hline 8.56 & 1.38 & 1.54 \\
\hline 11.32 & 1.76 & 2.82 \\
\hline 19.12 & 2.95 & 3.05 \\
\hline 19.48 & 2.98 & 2.98 \\
\hline 19.87 & 3.03 & 2.93 \\
\hline 19.44 & 2.98 & 2.26 \\
\hline
\end{tabular}

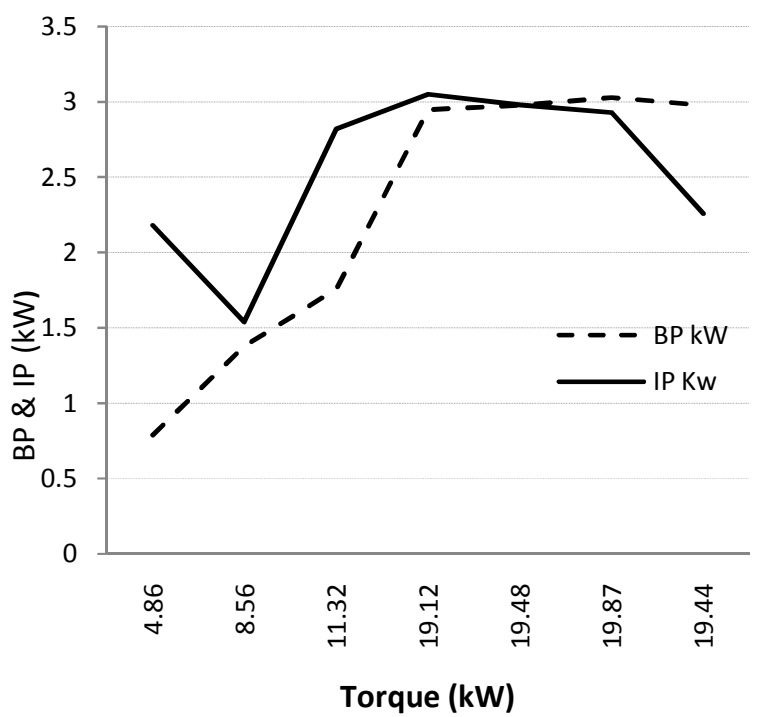

Chart -3: BP \& IP v/s Toque

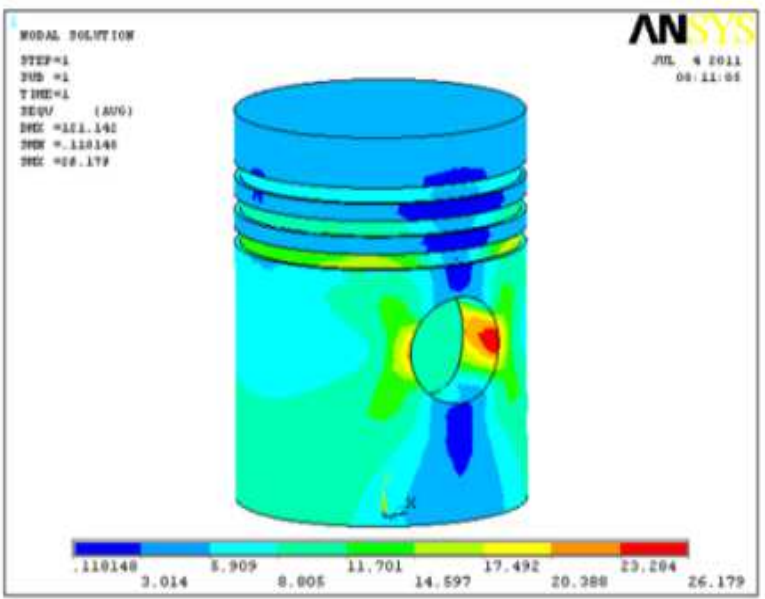

Fig -8: deformation zone in piston at TDC 


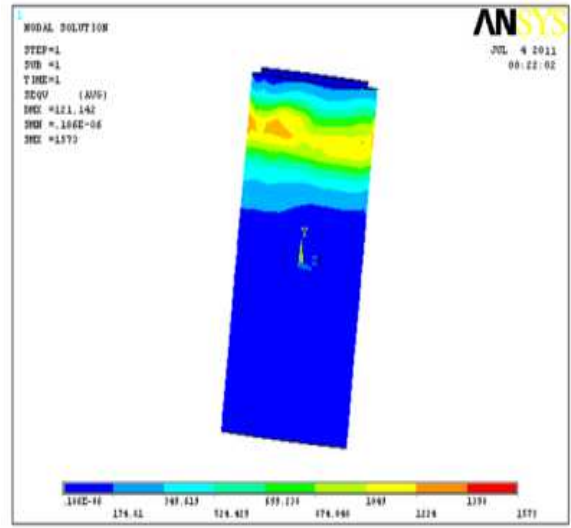

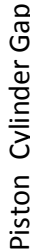

Fig -9: Distribution of stresses in piston-cylinder assembly at TDC

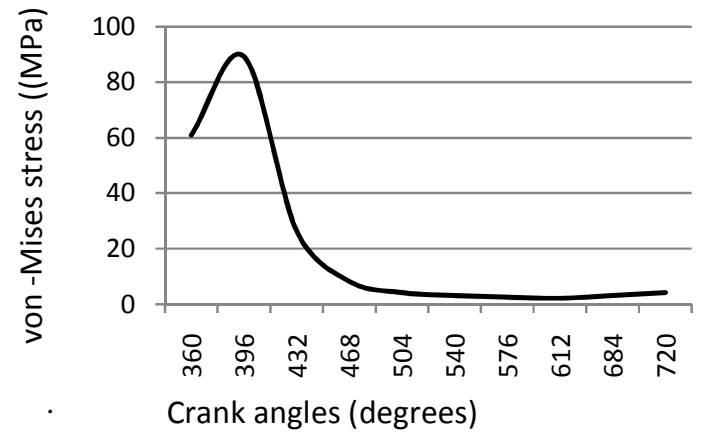

Chart -4: Variation of von Mises stress for different crank angles

From the finite element analysis, the stress and displacement values have been found out corresponding to the gas pressure taken from the engine readings and are tabulated. The 3600 crank angle corresponds to the TDC of the piston position in the cylinder. From Chart-1, the pressure v/s crank angle, it is evident that the maximum pressure of 56 bars is observed near TDC. Hence the structural analysis of the piston is taken from TDC to BDC travel during power stroke i.e. after combustion of fuel in the chamber. From the Chart- 4 it is observed that the stress in the piston is maximum near the 56 bars pressure regions and causes the piston to deform more at this region. For cylinder also the high stress region is observed near TDC (Fig-10). The displacement curves are plotted to study the piston lateral motion (perpendicular to the axis of the piston reciprocating motion) which is observed from piston displacement in x-direction(Fig-10).

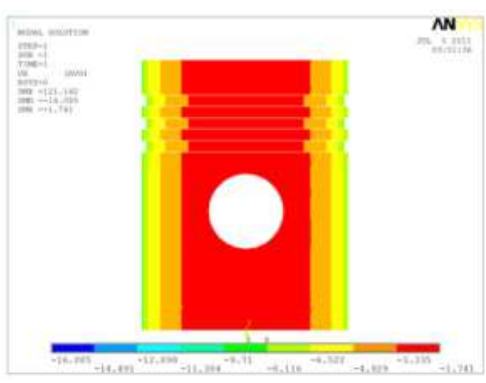

Fig -10: Piston Deformation along $\mathrm{X}$-axis

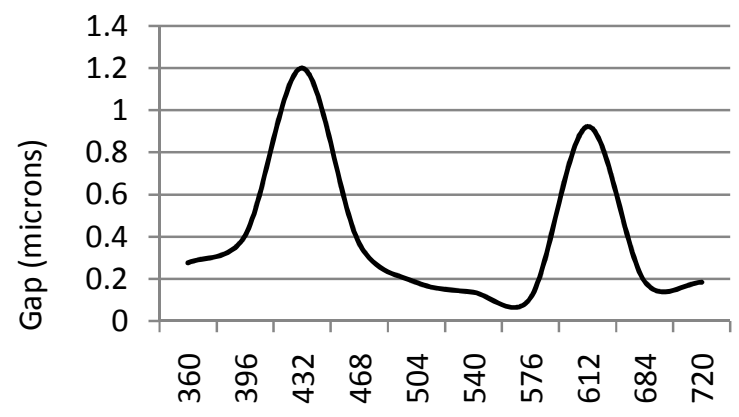

Crank angles (degrees)

Chart -5: Variation uı pisıun-cyınue gap ivi unierent crank angles

Hence the gap between piston and cylinder reduces in the high stress region which corresponds to the higher torque values compared to the other region. This behavior of the piston lateral motion repeats for regular interval of the crank angle between 00 to 7200 of the complete cycle. The results obtained from the multi-body dynamic analysis (MBD) are discussed as follows. The stress distribution in the engine components is shown in the Fig - 11. It is observed from the MBD analysis that the combined effect of the various forces acting on the engine components viz., connecting rod, crankshaft and piston, is inducing stress in each component. The maximum stress level in the piston is observed as $3.584 \times 102 \mathrm{~N} / \mathrm{mm} 2$. The maximum displacement observed as $1.710 \mathrm{~mm}$.
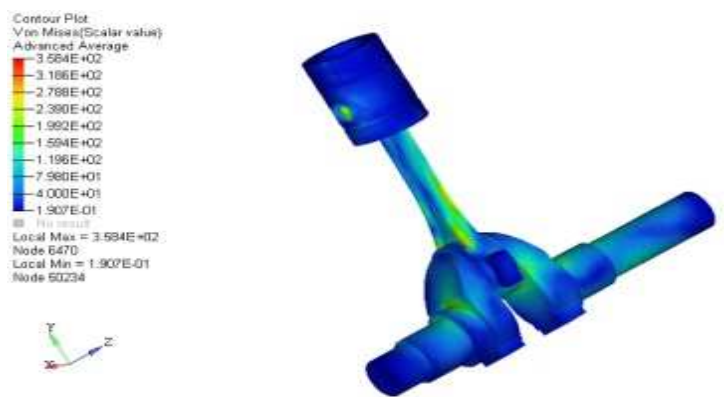

Fig -11: von Mises stress distribution of MBD analysis of engine 
From the MBD analysis it is evident that the maximum stress region is observed near TDC, where the engine pressure and torques are maximum. The pressure variation from TDC to BDC plays an important role in delivering the output power of the engine. For maximum torque the piston experiences maximum pressure and this corresponds to the high stress region. The maximum displacement is also observed in this region. Hence piston experiences maximum displacement and contributes to the lateral motion of the piston. This causes the piston to slap/tilt to develop the engine vibration.

\section{CONCLUSIONS}

The structural analysis of the piston for the various pressure on the piston for different position of the piston in the cylinder moving between TDC to BDC have been studied and the following conclusions are made.

- The piston experiences maximum stress in the region where the combustion of the fuel takes place and the torque of the engine is maximum for initial speed.

- This high stress region in the piston deforms more than the other region of the piston. This deformation is proportional to the engine torque and pressure.

- The maximum $\mathrm{x}$-displacement of the piston for structural analysis resembles the maximum displacement of the piston in MBD analysis. Hence the piston experiences maximum displacement in this region.

- The deformation in the piston causes it to displace more in this region and this cycle repeats even for the reduction in combustion pressure.

- The MBD analysis confirms the relative motion between the parts and reveals that the engine noise is associated with the maximum stress developed in the engine parts.

The future scope of this work includes carrying out MBD analysis, to incorporate the forces in motion for prediction of piston slap and optimization of the geometry of the piston to reduce engine noise and vibration $(\mathrm{NVH})$.

\section{REFERENCES}

[1] S.N.Kurbet and R.Krishnakumar "A Finite Element study of Piston Tilt effects on Piston Ring Dynamics in IC Engines Proc Instn Mech Engrs (IMECHE) Part K.2004, pp 107-117.

[2] Vinay.V.Kuppast and Dr. S.N.Kurbet, 'Review of Finite Element Analysis of the IC engine noise and its experimental validation'. International Conference on Total Engineering Analysis,IISC,Bangalore.2008.

[3] Toshiyaki Kobayashi, Yukitaka Takahashi and David J. Bell, 'How to predict the piston slap-noise using 3D piston motion simulation', SAE International, 2007-01-1245, 2007.

[4] R.R.Malagi and S.N.Kurbet "A Comprehensive Model to Study Dynamic Motion of Piston and Friction and
Lubrication in IC Engines" Journal of Tribology Trans ASME Tribo-08-1024.

[5] Nagaraj Nayak , P.V. Reddy, Yogesh Aghav, Navtej Singh Sohi and A.D.Dani, 'Study of engine vibration due to piston slap on single cylinder, high powered engine', SAE Iternational,2005-26-046,2005.

[6] R.R.Malagi and S.N.Kurbet, 09073 Stress analysis of Piston Ring -FE approach, , 2nd International Conference on recent Advances in Manufacturing held at Kovilpetti TN from 25-27 Feb 09.

[7] Robert L. Nortan, 'Design of machinery', TATA Mc Graw Hill Publishers, Delhi.

[8] Ibrahim Zeid, 'CAD/CAM Theory and Practice' Tata Mc Graw Hill Publishers, Delhi.

\section{BIOGRAPHIES}

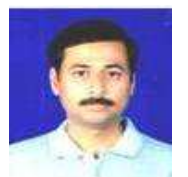

Mr. Vinay V. Kuppast is presently working as an Associate Professor in Department of Mechanical Engineering, BEC, Bagalkot of Visvesvaraya Technological University, Belgaum. His field of research interests is MBD, NVH and PLM.

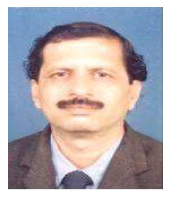

Dr. S. N. Kurbet is presently working as a Professor and Head, Department of Mechanicl Engineering, BEC,Bagalkot of Visvesvaraya Technological University, Belgaum. His field of interest is CAE, FEA and HRD in engineering. $\mathrm{He}$ is presently guiding $5 \mathrm{Ph} . \mathrm{D}$ students and 3Ph.D students have been awarded.

Dr. Aravind M. Yadawad is presently working as an Associate Professor in Department of Mechanical Engineering, NIE, Mysore of Visvesvaraya Technological University, Belgaum. His field of research interests is CAE, Energy Engineering and Management.

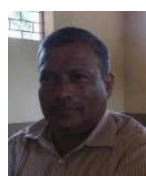

Mr. G. K. Patil is presently working as an Associate Professor in Department of Mechanical Engineering, BEC, Bagalkot of Visvesvaraya Technological University, Belgaum. His field of research interests is Kinematics and Dynamics of Machinery, Energy Engineering and Management. 